\title{
Influence of Rewards and Recognition on Employees' Motivation and Job Performance: Path Analysis Approach
}

\author{
S. Meena', T. Girija² and D. Visagamoorthi ${ }^{3}$
}

\author{
'Department of Management Studies, Vels Institute of Science, Technology and Advanced studies, \\ Chennai-600117, Tamil Nadu, India; meena.sms@velsuniv.ac.in \\ 2School of Management Studies, SSN College of Engineering, Chennai - 603110, Tamil Nadu, India; \\ girijat@ssn.edu.in \\ ${ }^{3}$ School of Management, Sri Krishna College of Engineering and Technology, Coimbatore - 641008, Tamil Nadu, \\ India; visad@rediffmail.com
}

\begin{abstract}
Objectives: To study the influence of rewards and recognition on employees' motivation. To identify the influence of employees' motivation on job performance. Methods/Statistical Analysis: Descriptive research design is adapted for this study. Convenient sampling technique was applied and data was collected from 114 respondents. As 4 responses had flaws 110 response was considered for analysis. The sample considered for the study was 110, excluding the 4 questionnaire with flaws. Path analysis was adopted for primary data analysis. Findings: It was found that rewards and recognition has influence on employees 'motivation. This has achieved support from earlier studies and few others. The research also found that there is influence of employees' motivation on job performance and this supports the findings. It was also found that there is relationship between reward and recognition, this result is supported. Bank management provides updated rewards and recognition which the employees like and in turn this may help to increase employee motivation and its influences employees' performance and its influences bank performance. Application/Improvements: Thus to improve the performance of the employees the rewards and recognition need to be updated according to the requirement of the employees. Continuous research must be conducted to identify the type of reward that motivates the employees and the reward system need to be reframed in organization
\end{abstract}

Keywords: Employees' Motivation and Job Performance, Recognition, Rewards

\section{Introduction}

As manpower comprise the heart of all business and eventually workers are the major hub of HRM, with the regular alterations happening in the world nowadays, particularly with consider to innovation and technology, there is a require for corporations to reconsider the way in which they converse to their workers, which would enlarge their confidence and will act as a powerful force towards an incorporated employees. Hence, distant from financial remunerations there are other earnings to reward workers, a few of which contain the honor that workers are capable to obtain from their administrators the chance to get on essential missions or responsibilities, and smooth leadership concentration which assists them clamber Maslow's pyramid of requirements to achieve inspiration for enhanced organizational performance.

Employee recognition is a decision on an employee's contribution, in conditions of the work procedure as well as commitment and inspiration. It also occupies 
estimate and recognizing the outcome of this occupation. It is too necessary to study and appreciate the scope to which the above mention issues have an influence on the employment strength considering the entire negative and positive things gratitude have on organizational growth.

Job performance is an action that involves process and product (final output). The individual process can be influenced by an organizations' overall performance. It is not only actions that determine one's performance but also external factors such as resources, organizational culture and economic, political and social factors. The most important need of the study is to initiate innovative techniques of gratitude for workers. The research would assist organizations structure newest employee motivation programs. It would help the employees in future to increase their job performance.

\section{Literature Survey}

In ${ }^{1}$ researched that the entailed on "Employee Motivation Measurement". The data was collected from 40 employees of engineering firm of Bangladesh. The research was found that the influence of rewards, salary, job characteristics, recognition and appreciation, working conditions, training and development, performance appraisal, job security, leadership and promotion on motivation.

$\mathrm{In}^{2}$ studied on "impact of recognition and reward programs on employees' motivation and satisfaction". Sample of the study was 80 employees of UNILEVER companies. The analysis found that there is influence of Payment, Work Content, Working conditions, Promotion, Recognition, Personal, Benefits, rewards and general on employee's motivation and satisfaction.

$\mathrm{In}^{\underline{3}}$ studied on "impact of rewards and recognition on employee motivation" descriptive research design was adopted. Sample size was 50 employees through convenience sampling. Chi-square test, correlation were used for data analysis. The researchers found that there is influence of recognition and rewards on employee motivation.

$\mathrm{In}^{4}$ researches that the entitled on "relationship between reward and recognition and employees job satisfaction." The research was focused on previous research. The research found that there is a positive relationship between employee's job satisfaction and recognition and reward. The research also suggested that the business organizations can attain their objectives and plans during provoked employees and efficient recognition and reward system.
$\operatorname{In}^{5}$ studied on "impact of recognition and reward programs on employees' motivation." The research was carried out in Srilank. Sample size was 80 employees of Commercial Banks. The analysis found that is a positive relationship between recognition, rewards and motivation.

$\mathrm{In}^{6}$ analyzed that the entailed on "relationship between motivation and job satisfaction." 120 employees were selected for the study. The research found that there is correlation between motivation factors with job satisfaction.

\section{Research Methodology}

\subsection{Research Design}

Descriptive research method has been followed in organizing this research work. The descriptive research attempts to describe the behavior of the respondents in relation to a particular practice or culture of importance.

\subsection{Framework}

Altogether this study includes four different variables. Rewards and the recognition were the independent variables; employees' motivation was dependent variables; Job performance was the outcome variable as shown in Figure 1.

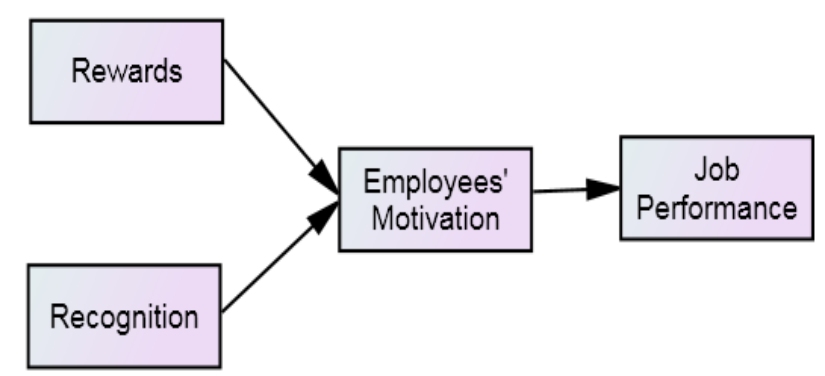

Figure 1. Conceptual framework of employee motivation on job performance.

\subsection{Objectives of the Study}

- To study the influence of rewards and recognition on employees' motivation.

- To identify the influence of employees' motivation on job performance.

\subsection{Hypotheses of the Study}

- There is no influence of rewards and recognition on employees' motivation.

- There is no influence of employees' motivation on job performance. 


\subsection{Instruments Used for Data Collection}

A well-designed questionnaire was used to gather the data for this research. The questionnaire contains four sections are presented. The Section 1 was constructed to obtain the demographic profile of the participants; The Section 2 scale was used to know the rewards and recognition; the Section 3 was used to know the employees' motivation; the section 4 was used to analyze the employees' job performance.

\subsection{Reliability Analysis}

Reliability analysis was also applied to test the reliability of the factors presented in Table 1. The reliability range from 0.80 to 0.92 , which satisfies the Cronbach's alpha, should be at least 0.70 to be considered as acceptable.

Table 1. Reliability analysis of the factors

\begin{tabular}{|c|l|c|}
\hline S.No. & \multicolumn{1}{|c|}{ Variable } & Reliability \\
\hline 1 & Rewards & 0.82 \\
\hline 2 & Recognition & 0.80 \\
\hline 3 & Motivation & 0.92 \\
\hline 4 & Job performance & 0.87 \\
\hline
\end{tabular}

\subsection{Area of Sample and Justification}

Chennai district have been chosen for this study as area of sampling. Hence there is a need to protect and develop the employees as well as the organization as a whole. The sample includes the employees of private sector banks in Chennai district of Tamil Nadu.

\subsection{Sample Size}

Totally 125 questionnaires were distributed. 114 questionnaires were received. 11 questionnaires were not received. Out of 114 received questionnaires 110 were eligible and the remaining 4 were with flaws. Hence, the sample size considered for the study was 114 .

\subsection{Sampling Technique}

Convenience sampling technique is dictated only by the researcher's convenience and not to other considerations. There is only a less effort needed to collect the data. Actually no pre plan of executing is there.

\subsection{Tool for Data Analysis}

Path analysis was adopted for primary data analysis. Rewards and the recognition were the independent variables; employees' motivation was dependent variables; Job performance was the outcome variable.

\section{Analysis and Interpretation}

The results shown in Table 2-4 are indication of the model fit, which contains the chi-square value (3.194), and probability value $(0.203)$. In this model, the researcher has obtained GFI was 0.974 , the AGFI was 0.912 the Normal fit Index was .990 and Compared Fit Index was 0.992 as against the recommended level. RMSEA was 0.067 and is well nearby the recommended limit of 0.05 as shown in Figure 2.

Table 2. Model fit indication

\begin{tabular}{|c|c|l|}
\hline Indicators & Observed Value & Recommended Value \\
\hline Chi-Square & 3.194 & --- \\
\hline $\mathbf{p}$ & 0.203 & Greater than 0.050 \\
\hline GFI & 0.974 & Greater than 0.090 \\
\hline AGFI & 0.912 & Greater than 0.090 \\
\hline CFI & 0.992 & Greater than 0.090 \\
\hline NFI & 0.990 & Greater than 0.090 \\
\hline RMSEA & 0.067 & Less than 0.080 \\
\hline
\end{tabular}

Source: Primary data

Table 3. Regression weights

\begin{tabular}{|l|c|l|c|c|c|c|c|}
\hline DV & & \multicolumn{1}{|c|}{ DV } & Estimate & S.E. & C.R. & Beta & P \\
\hline Employees' Motivation & $\leftarrow$ & Rewards & 0.063 & 0.007 & 8.670 & 0.712 & $* * *$ \\
\hline Employees' Motivation & $\leftarrow$ & Recognition & 0.026 & 0.010 & 2.511 & 0.206 & 0.012 \\
\hline Job Performance & $\leftarrow$ & Employees' Motivation & 0.796 & 0.054 & 14.695 & 0.886 & $* * *$ \\
\hline
\end{tabular}

Source: Primary data 
Table 4. Covariance

\begin{tabular}{|l|l|l|l|l|l|l|l|}
\hline IV & & IV & Estimate & S.E. & C.R. & R & P \\
\hline Recognition & $<-->$ & Rewards & 8.760 & 3.762 & 2.328 & 0.318 & 0.020 \\
\hline
\end{tabular}

Source: Primary data

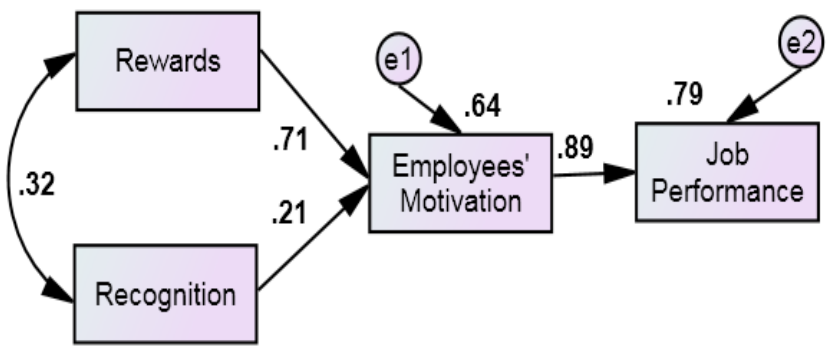

Figure 2. Model fit indication of employee motivation on job performance.

All the goodness of fit indicators falls into best level of fit as suggested by 7.8 .

$\mathbf{H}_{01}$ : Rewards has significant has no influence on employees' motivation.

Influence of rewards on employees' motivation computed CR value was 8.670 and the probability value was 0.001 . Hence, the hypothesis was rejected. The computed standard regression weight was 0.712 . It shows that the one unit increase of rewards leads to increase of 71.2 percent on employees' motivation. Hence, it is concluded that influence of rewards on employees' motivation.

$\mathbf{H}_{02}$ : Recognition has no significant influence on employees' motivation.

Influence of recognition on employees' motivation computed CR value was 2.511 and the probability value was 0.012 . Hence, the hypothesis was rejected. The computed standard regression weight was 0.206 . It shows that the one unit increase of recognition leads to increase of 20.6 percent on employees' motivation. Hence, it is concluded that influence of recognition on employees' motivation.

$\mathbf{H}_{03}$ : Employees' motivation has no significant influence on job performance.

Influence of employees' motivation on job performance computed CR value was 14.695 and the probability value was 0.001 . Hence, the hypothesis was rejected. The computed standard regression weight was 0.886 . It shows that the one unit increase of employees' motivation leads to increase of 88.6 percent on job performance. Hence, it is concluded that influence of employees' motivation on job performance.

$\mathbf{H}_{04}:$ Rewards has no significant relationship with recognition.

Relationship between rewards and recognition computed CR value was 2.328 and the probability value was 0.001 . Hence, the hypothesis was rejected. The computed co-efficient weight was 0.318 . Hence, it is concluded that rewards has significant relationship with recognition. The current research has achieved support from the earlier studies.

\section{Findings and Recommendations}

\subsection{Findings}

- The analysis found that there is influence of rewards and recognition on employees' motivation.

- The research also found that there is influence of employees' motivation on job performance.

- It is also found that there is relationship between rewards and recognition.

\subsection{Recommendations}

- Appreciation agenda should be accomplished which helps in inspiring the employee. To encourage the employee's managements can provide appreciation like awards and rewards, to the best performer and it helps to encourage the employees and increase the employees' motivation.

- Management should provide recognition and rewards. It will ultimately lead to job motivation and employees' performance among employees in the banking sector.

\section{Summary and Conclusion}

Motivation denotes derives, desire and wishes to reach the objectives and targets. It is the major set of factors that achieved the victory of any business organizations. The employees can be motivated only by rewards of money and appreciate recognition for a job done. The main aim of the study was to find out influence of rewards and rec- 
ognition on employees' motivation and job performance. Research methodology techniques such as descriptive research design, sample size was 114 , convenience sampling technique and path analysis was used. The analysis found that there is impact of recognition and rewards on employees' motivation. The research also found that there is influence of employees' motivation on job performance. Hence, It is concluded that bank management provide updated rewards and recognition which the employees like and in turn this may help to increase employee motivation and its influences employees performance and its influences bank performance.

\section{References}

1. Talukder A, Mohammad Saif AN. Employee motivation measurement- A descriptive analysis. Bangladesh Journal of MIS. 2014; 6(2):123-31.

2. Ali R, Ahmed MS. The impact of reward and recognition programs on employee's motivation and satisfaction: An empirical study. International Review of Business Research Papers. 2009; 5(4):270-9.

3. Baskar Prakash DR, Rajkumar KR. A study on the impact of rewards and recognition on employee motivation.
International Journal of Science and Research. 2015; 4(11):1644-8.

4. Zeb A, Rehman S, Saeed G, Ullah H. A study of the relationship between reward and recognition and employees job satisfaction: A literature review. Abasyn Journal of Social Sciences. 2014; 7(2):278-91,

5. Jayarathna P. The impact of reward and recognition programs on employees' motivation in Commercial Bank, Sri Lanka. 12th Annual Research Symposium, University of Kelaniya; 2011. p. 1-9.

6. Research study on the correlation between employee job satisfaction and employee motivation. Available from: https:// www.researchgate.net/publication/236008924

7. Velaudham C, Baskar P. Number of earning members influence over air conditioner buying behavior: multiple group analysis approach. Annamalai Business Review. 2016; 10(2):59-8.

8. Premapriya MS, Velaudham C, Baskar P. Nature of family influenced by consumer buying behavior: multiple group analysis approach. Asian Journal of Research in Social Sciences and Humanities. 2016; 6(9):908-15. https://doi.org/10.5958/2249-7315.2016.00841.8 